\title{
Design and pre-testing of a mobile modular floating platform with adjustable displacement
}

\author{
Projekt i badania wstępne mobilnej modułowej \\ platformy pływającej o regulowanej wyporności
}

WIESŁAW KRASOŃ PAWEK SŁAWEK *

Contemporary emergency crossing systems used by military and crisis service systems are constantly evolving and have to meet many requirements. As a result, modifications to the prototype pontoon bridge segment with adjustable displacement, are proposed. The floating cradle system has been upgraded, additional displacement modules have been supported and a number of solutions including floating equipment and fittings have been added. Modifications and developed constructions allow not only to combine traditional ribbon bridges, but also mobile floating platforms with self propulsion. Assumptions and solutions used in the ferry built from adjustable displacement cassettes, have been focused on. Concept of the ferry in basic configuration and selected variants of strength tests of the shore module of such ferry, is also discussed.

KEYWORDS: prototype cassette, floating platform, adjustable displacement, innovative construction solutions, numerical analysis

Many floating systems are now available that allow to set up different configurations of pontoon bridges and ferries. An example is the PFM pontoon bridge [1], which allows for the construction of ferry boats with a displacement of $700 \mathrm{kN}$ (fig. 1a). Each block of this system has two outboard engines of 75 hpwith an anchoring system and the possibility of connecting with two types of ramps. This solution has found a number of uses, mostly the military ones [1]. In Poland, apart from the PP-64 Floating Park, already withdrawn from the army, there is no floating system, which would provide the possibility of building bridges and ferries with technical and operational parameters required by the military or crisis services.

An innovative solution to meet these challenges is a floating system developed at the Military University of Technology based on a prototype floating cage with adjustable displacement (fig. 1b) [2]. By applying a highstrength elastic shell filled with compressed air placed inside a metal cassette with a movable bottom, the displacement force can be adjusted depending on the type of cross-over. Opening the cassette, expanding the flexible pontoon, displacing the cassette bottom, and changing the displacement of the single floating module, are the result of filling the pontoon with compressed air. Emptying the pontoon and closing the cassette is made possible by the use of 10 telescopes, in which spring assemblies of appropriate rigidity are built. The
DOI: https://doi.org/10.17814/mechanik.2017.11.185 telescopes were placed symmetrically on both sides of the cassette (fig. 1b).

In a closed state prepared for transport, a single cassette can float, because it has a load capacity, which allows it to be mounted immediately after launching, and even the use a limited range, without inflating the pontoons. The service life of a single closed bottom cassette is approximately $5 \mathrm{kN}$. In addition, a movable protective plate is used in the forepart of the cassette - a deflector that automatically positions itself with the bottom of the cassette and the opening of the cassette [2]. Its main function is to reduce the force of the pressure on the flexible pontoon and to protect it from damage.

Prototype floating cassettes can be combined depending on the need for different crossing groups. This is done using the mechanical mechanisms that constitute the set of locks [2] shown in fig. $1 b$.

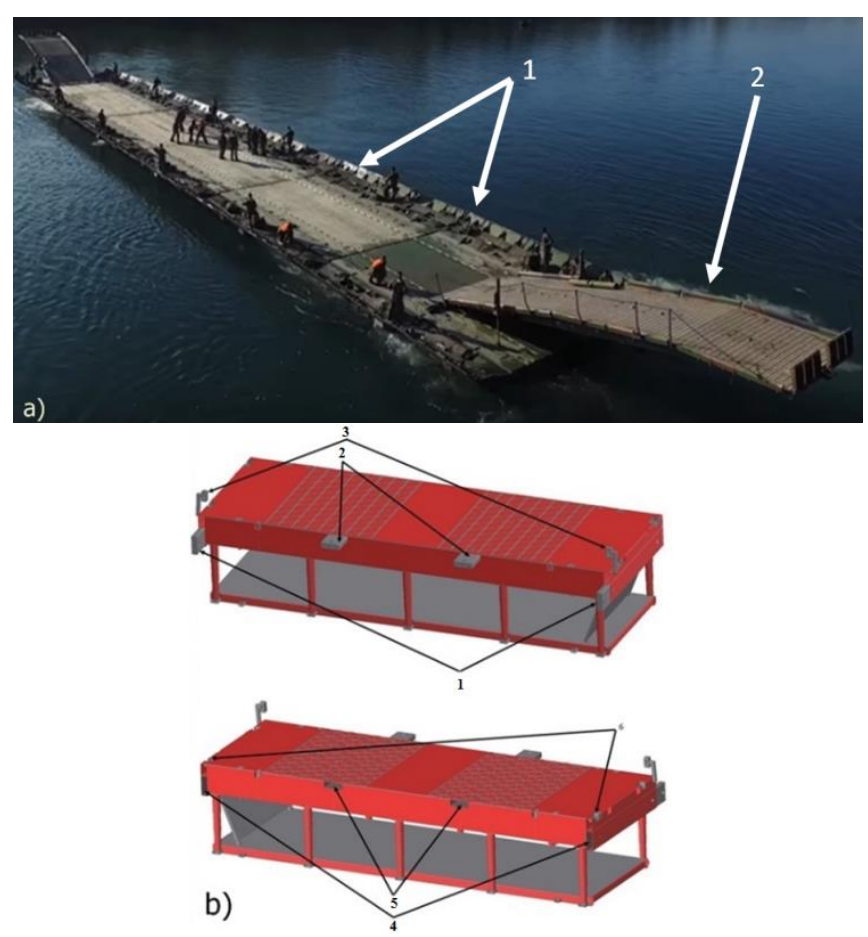

Fig. 1. PFM system when operating on water: 1 - single segment of PFM system [1]; 2 - ramp with adjustable position (a). Single prototype cassette after opening the bottom: 1 vertical plungers; 2 - horizontal spindles; 3 - rotating arms; 4 vertical fixing pins; 5 - pins for fixing the spindles; 6 - swivel arm mounting sockets [2] (b) 
In the group of joints, the vertical mandrels ( 1 in fig. $1 b)$ and the horizontal ones (2) are arranged symmetrically in the upper part of the cassette, which are inserted into the cassette during transport and locked in the cradle of the cassette. Connecting the cassettes is done by inserting the vertical and horizontal pins into the fixing sockets $(4,5)$ of the adjacent cassette. In addition, each cassette is equipped with two rotary arms (3) which, during transport, are positioned in the holes (6) at the top of the cassette (to protect them from damage). They allow to locate and connect adjacent cassettes in the carriageway. The connection is made by rotation of the rotating arms, placement of the heads and their locking in the slots (6) made in the pavement of the adjacent cassette.

Modifications in the design of a single segment of a prototype floating cassette are presented. Modifications based on the initial assumptions described in detail [3] include a reduction in the total weight of the system, increased displacement, improvement of its shape and adaptation of the cassette construction to the construction of a floating modular floating platform and various floating ribbons. The design of the propulsion system, the anchoring system and the on-shore ramp described in [4] are proposed. Selected solutions introduced for the construction of mobile floating platforms are discussed; particular attention has been paid to the original, floating displacement of floating modules - overlays and an edge-to-edge ramp suitable for the use on both mobile platforms and, to a limited extent, floating bridges. As part of the design work, the necessary tests of structural strength have been performed. Analytical methods and numerical analysis were used. The paper presents selected variants of the strength of the edge module for such a ferry using the numerical analysis of the FEM.

\section{Single cassette modifications}

Various modifications have been introduced [3, 4] in order to change the cassette coupling system, to introduce a number of additional solutions in the equipment and equipment of the floating system and to improve the displacement and technical performance of a single cassette. Changes in the design of a single floating cassette with a total output weight of $2,488 \mathrm{~kg}$ included:

- removal of the deflector (protective plate mounted only in the forward part of the cartridge caused uneven weight distribution and trim of this segment during launching);

- in the prototype solution [2], the plating (fig. 2) is made of a sheet of $5.95 \times 1.78 \mathrm{~m}$ steel sheet and $1.5 \mathrm{~mm}$ thick; in the proposed solution, this sub-assembly is recommended to be made of PMMA (polymethyl methacrylate) plastic; the main purpose of plating is to ensure even distribution of the force generated during the cradle bottom distribution and to protect the elastic coating from damage;

- incorporation of transport connectors - in the prototype version of the floating cassette, no transport couplings were designed to allow it to be moved (mainly for loading or unloading from a transport rack or in

\footnotetext{
* Dr inż. Wiesław Krasoń (wieslaw.krason@wat.edu.pl), mgr inż. Paweł Sławek (pawel.slawek@wat.edu.pl) - Katedra Mechaniki i Informatyki Stosowanej, Wydział Mechaniczny Wojskowej Akademii Technicznej
}

launching and taking off water); four connectors (fig. 2) are placed symmetrically on both sides of the cassette; in each of these joints, an "omega" steel shovel with an allowable working load of $47.5 \mathrm{kN}$ was selected. In order to minimize the loading space, the number of elements extending beyond the outline of the cassette and the likelihood of damage to the transport connectors, the shackles are freely rotatable and placed in slots below the ground plane;

- insertion of the cassette coupling ports in the bow-stern part - the mechanical lock assemblies in the prototype floating cassette (fig. $1 b$ ) only allow the joining of single webs of any length. In order to allow for the configuration of both ferry and floating bridges, it is necessary to create in the bow and stern part, the sockets forming the base part for the additional spindles connecting the cassette segments (fig. 2). Mirroring features on the opposite side are applied to ensure the versatility of handling when bonding to a double ribbon and restricts maneuvering to a cassette or cassette assembly. An additional safeguard against undesirable free disconnection of the cassettes in the form of a double-sided screw connection was also introduced;

- spring-telescopic system: a single telescope (fig. 2), which attaches to the movable bottom of the cassette, consists of four cylinders of different diameters, joined by flanges and cooperating with the spring assembly. The purpose of the system is to ensure a smooth movement of the bottom of the cassette during air filling and emptying of the pontoon. The changes come down to the minimum, safe from the point of view of strength and operation of the wall thickness of the individual cylinders without interfering with the design solution of the system. This treatment reduced the total weight of the spring-telescopic system.

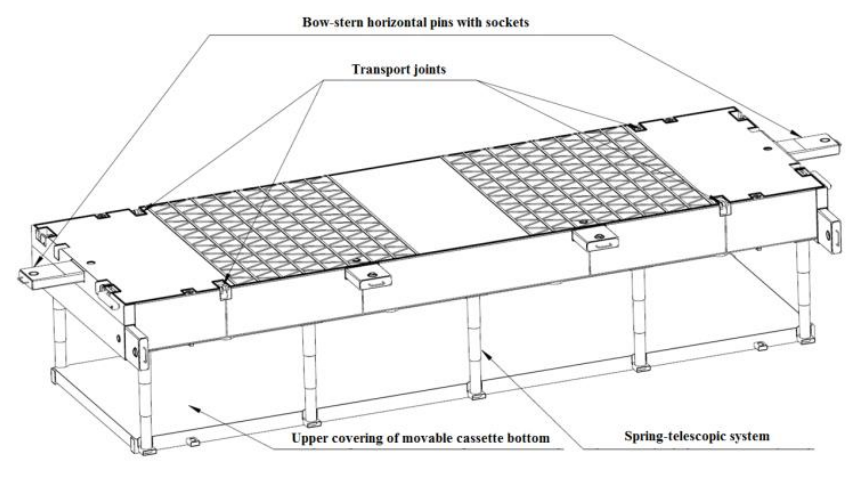

Fig. 2. Arrangement of sub-assemblies in the prototype floating cassettes after modification

As a result of the design changes, the total weight of the single floating cassette was reduced by $143 \mathrm{~kg}$ and reached $2,345 \mathrm{~kg}$. In addition, it was possible to build any configurations of floating ferries and bridges, uniform distribution of weight of the system and easy and fast access to transport connectors [3, 4].

\section{The concept of bow-stern modules (overlays)}

The bow and stern ends are the original components of the floating system. They act as deflectors - they provide a streamlined platform and reduce the movement resistance of the craft on the water, as well as protect the crew and increase the operating space of 
the system as a deck available to the crew. On the water side, the surface of the overlay is shaped at an angle of $45^{\circ}$ (fig. 3), which directs the streams flowing over the set.

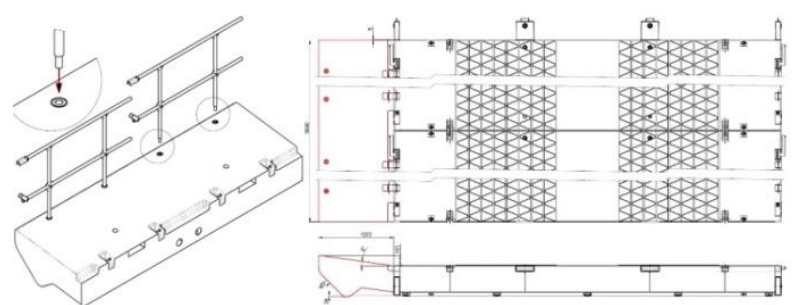

Fig. 3. Draft illustration of the bow and stern overlays; view of their fixation to the cassettes and protective barrier [4]

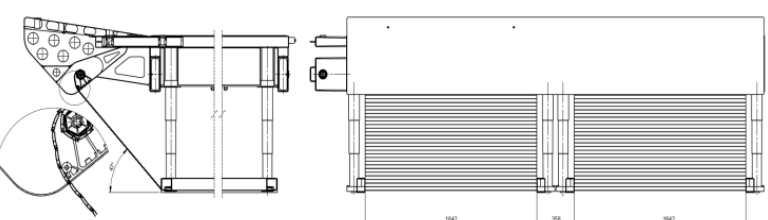

Fig. 4. Roller system construction in overlay module in basic version mounted on one side to two floating cassettes [4]

The use of lightweight materials and additional enclosed spaces (four sealed compartments) inside the structure allow for increased buoyancy of the entire set. A single base cover can be mounted simultaneously to a set of two cartridges set parallel to each other, with an overall length of $3,990 \mathrm{~mm}$. Overlay module in basic version has a usable displacement of approx. $18 \mathrm{kN}$. The structural design of this subassembly allows it to be joined to the beak or aft of the cassette and decides to increase the deck width of the cassette assembly by $1.2 \mathrm{~m}$ on each side.

Coupling to the cassettes is carried out using the bowstern couplings (figs. 2, 3), which carry the main load on these components. Additional protection against disconnection from the deck overlays is provided by the right set of bilateral screw connectors and screws M42 $\times 50$ in a horizontal spindle (fig. 3). The upper surface of the overlay module (fig. 3 ) is inclined towards the surface of the cassette carriageway by $8^{\circ}$, which may provide additional protection for the mobile floating platform crew and a warning that when leaving the deck, the members are near the outside edge of the floating set. The construction of the overlays makes it possible to install protective barriers made of plastic, which is the active protection of the crew.

Due to the removal of the protective plate (deflector) from the design of the floating cassette, protection should be provided for damage to the flexible pontoon and the proper orientation of the water jet after opening the cassettes and inflating the pontoons. For this purpose, the roller shutter system has been introduced(fig. 4).

The roller shutter system provides a streamlined shape for both the bow and sternparts of the cassette segment, which significantly reduces the resistance of the platform during the water movement. The selfwinding mechanism allows the rollers to be automatically expanded and folded together with the bottom of the cassette. The proposed roller shutter system is based on commercially available components, typically used for the construction of roller shutters, including: PE41 aluminum panels, self-winding mechanism, hook hanger or winding pipe. There are two roller shutter systems with guide rollers (fig. 4).

\section{Design and results of the strength tests of the ferry ramp}

An important element of the floating platform is the shore ramp. It is used to connect the platform deck - a set of floating cassettes - with the shore. It is used mainly during loading or unloading stage of the platform, but should be designed to be able to move along with the platform. According to the assumptions [3], design of the ramp is to allow unilateral connection to the deck of the cassettes by means of vertical spindle locks (fig. $1 b$ ) and the backrest of the entire plane of the bottom or only its part of free end of the ramp to the ground of the shore or obstacles. The floating ramp consists of two segments: the ramp and modified cassette with stationary, reinforced bottom - the intermediate segment. Both elements are made of S355J2 steel and form sealed welded hulls, consisting of an internal skeleton in the form of cold-formed profiles and sheet metal plating. In order to reduce the loading space during transport, a variant of the folding ramp with pivot connections (hinges in the carriageway) is used between the segments. This allows the ramp to be folded and disassembled into the transport position (fig. 5) or the working position (fig. 6) [4]. The gross weight of the ramp in this variant is approximately $3,110 \mathrm{~kg}$.
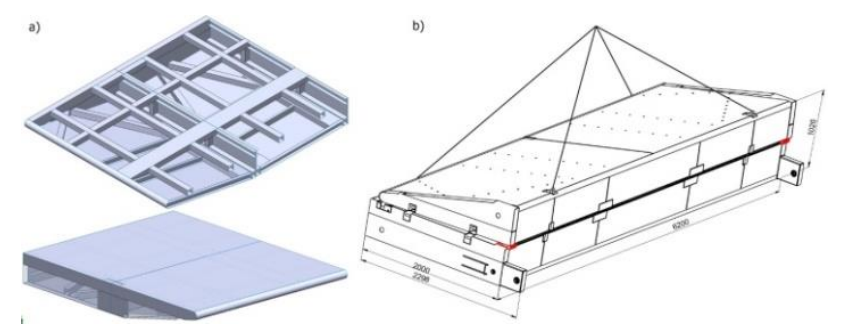

Fig. 5. Ramp-on-shore: a) geometric model of half of ramp, b) view of ramp prepared for transport in assembled condition with lifting ropes [4]

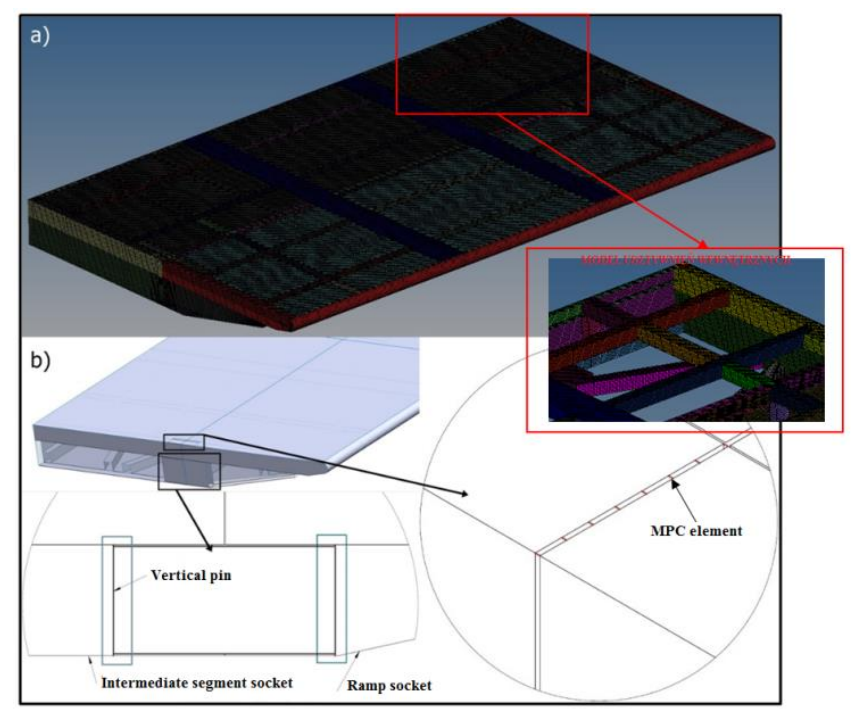

Fig. 6. FEM ramp model in working position: a) grid of QUAD4 elements in outer sheaths and in internal structure fragment; $b$ ) distribution of used MPC elements in ramp models

Numerical studies of the ramp structure were carried out using the 3D coating model (fig. 5a), which was made in Solid Works software based on the external walls of the actual profiles. In the geometric model, simplifications have been adopted that do not 
significantly improve the performance, but considerably reduce computational time. Furthermore, only half of the actual structure was constructed at the geometric model stage, because it is symmetrical (fig. 5a). The FEM model grid was made in Hyper Mesh (fig. 6a) [5]. The QUAD4 type elements were used on all surfaces, which were then copied using the mirror image to produce a complete discrete model (fig. 6a). After discretization, all components were given the strength properties characteristic of S355J2 (18G2A) steel and a linear material model was adopted. The FEM model was applied to the boundary conditions and the load was modeled in the MSC.Patransoftware [6]. The calculations were madewithin linear statics using MSC.Nastran [6].
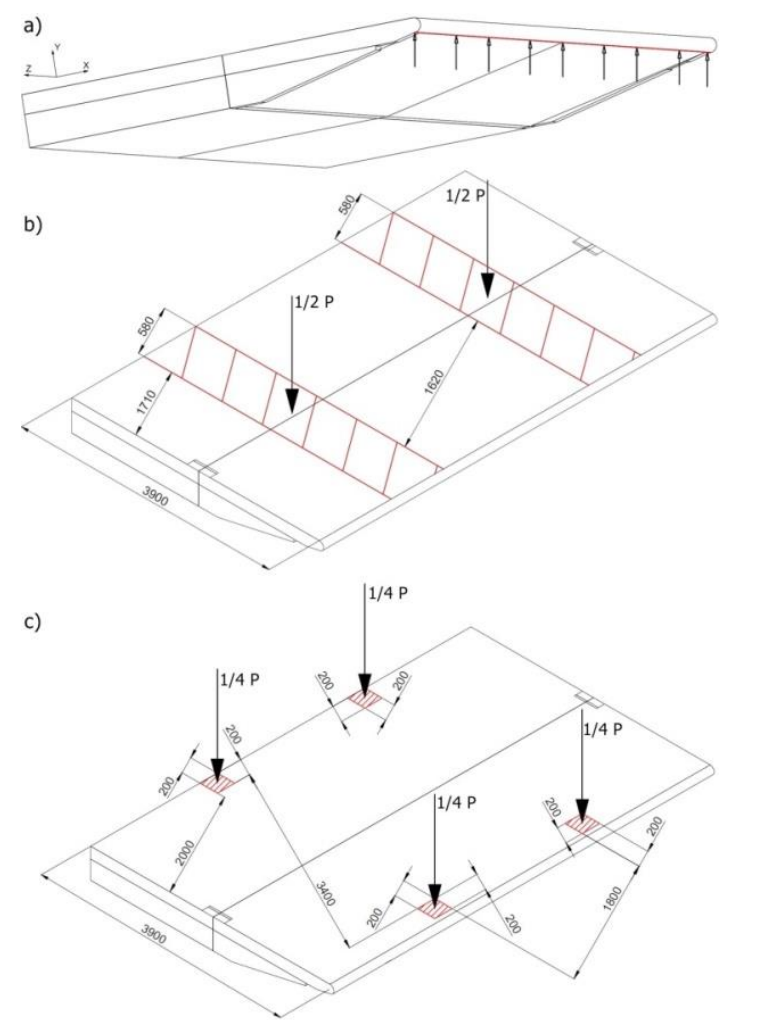

Fig. 7. Schemes of constraints and models: a) ramp support pattern in variants $A, B$ and $C ; b$ ) load pattern for variants $A$ and $D$ from crawler vehicle of $20 \mathrm{t}(P=200 \mathrm{kN})$; c) load pattern for variant $C$ from a wheeled vehicle of $20 \mathrm{t}(P=200 \mathrm{kN})$

The MPC-RBE2 kinematic elements (fig. 6b) were used to model the mechanical connections [6]. Their task is to transfer the load from one part to another, according to the linear relationship of the joined nodes by linking them with corresponding degrees of freedom. They were used to reflect the two-sided interaction with the vertical spindle socket, which is mounted on the side profiles of the ramp segments (fig. $6 b$ ). In addition, they are used to replace the bolt joints found in the roadway of the structure. These elements allowed to map the actual working conditions of the model [4]. Construction tests were carried out in five variants of support and load. The models of constraints and loads used in these variants of analysis are presented in fig. 7.

In each of the numerical analysis variants considered, the anchorage of the floating set with the mobile floating platform was reflected by means of the horizontal and vertical pins placed in the sockets. In the nodes at the outer edges of the jacks of the intermediate module, six degrees of freedom were obtained. In variants $A, B$ and
$C$, the nose support was modeled by using ball joints in the nodes along the entire length of its edges (fig. $7 \mathrm{a}$ ). In variants $D$ and $E$, they were replaced by vertical supports in all nodes of the lower ramp width $1 \mathrm{~m}$ from the nose edge. This way, a free support (without friction) of the ramping segment on unmanageable ground and distribution of the load on the surface of the bottom part of the ramp, was mapped.

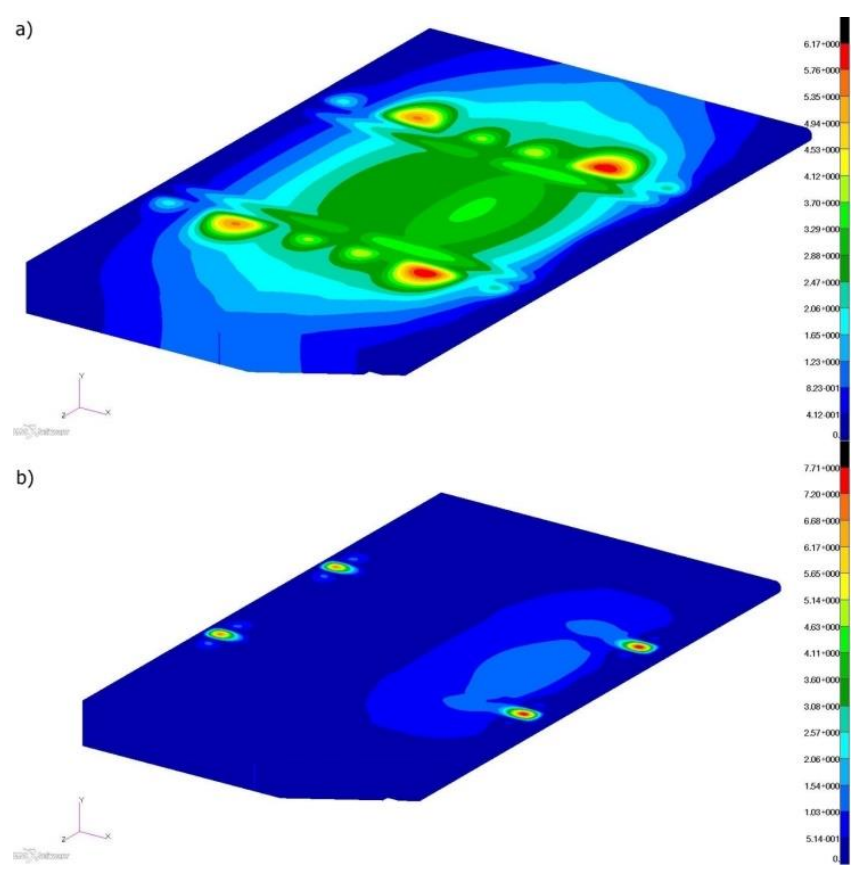

Fig. 8. Contour lines of accidentaldisplacements: a) calculation variant $A$ - crawler vehicle; $b$ ) calculation option $C$ - special wheeled vehicle

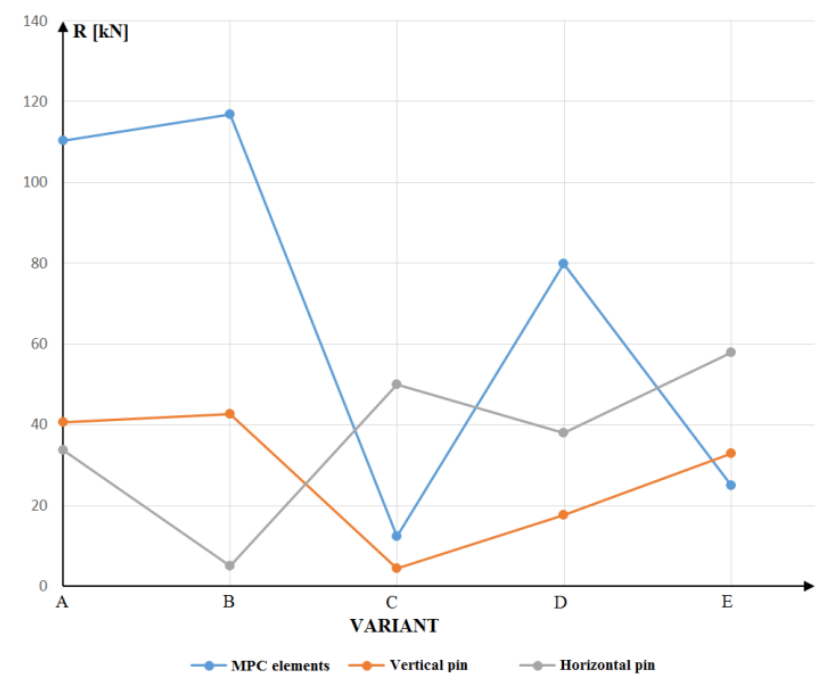

Fig. 9. Diagram of changes in maximal resultant force of the reaction force in the verticaland horizontal pins as well asin MPC elementsas the function of the variant considered

Two main load cases were identified for the analysis: from a crawler vehicle of $20 \mathrm{t}$ gross mass and a special firefighting vehicle of $20 \mathrm{t}$ gross weight and wheelbase characteristic for the MAN TGL 12.240. The load was realized by distributing the value of the vehicle's weight force on the surface of the dimensions characteristic of the individual variants presented schematically in fig. $7 b$ and fig. $7 c$. 

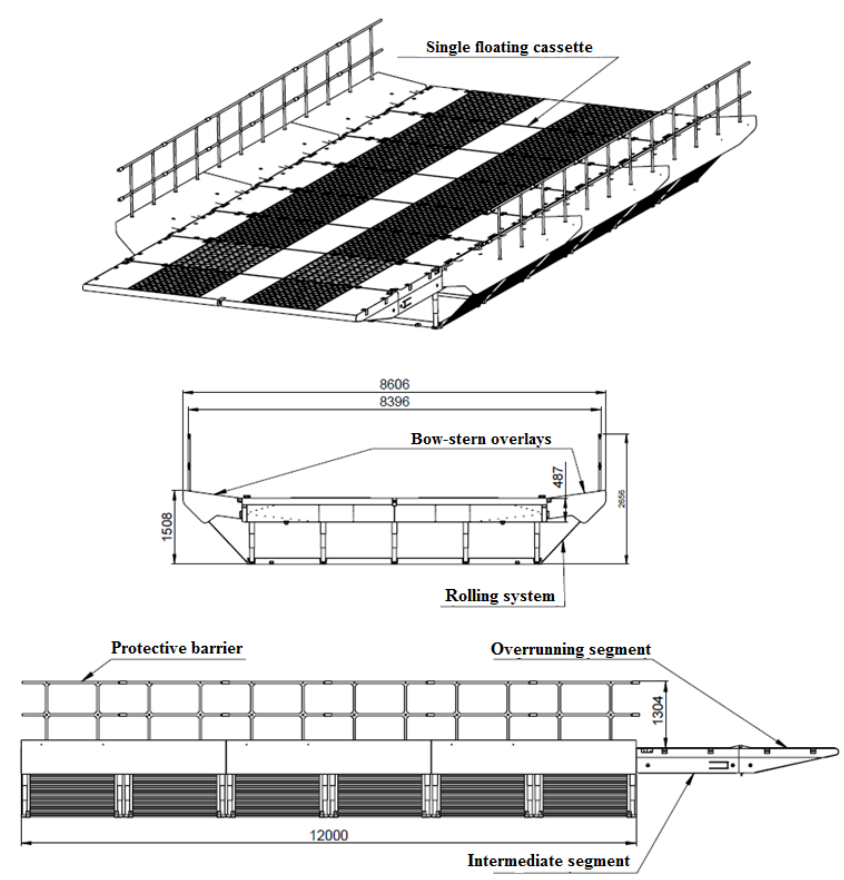

Fig. 10. Mobile floating platform in variant $1 \times 6$ including bowstern overlays and overrunning-edgeramp in three views

The FEM analysis in the field of linear statics allowed to obtain the $\mathrm{HMH}$ reduced stress contours and resultant contingencies. Displacements in variants $A$ and $C-$ corresponding to the load of the crawler and wheel vehicle - are compared in fig. 8. Accidental reaction forces were also identified in the supports - the vertical and horizontal spindles as well as the reaction forces in the MPC components modeling the pin joint (hinges in the ramp). Changes in the maximum reaction forces corresponding to the individual variants of the analysis are presented in graphs (fig. 9).

The maximum value of the reaction force of the bolt joints in the pavement plane of $116.9 \mathrm{kN}$ is in variant $B$, where the load is located directly at the joint of the floating segments of the floating set. At the same time, the components of the couplings are badly damaged due to the ramp variant used. Similarly, it appears in the case of vertical pins, where the maximum reaction force value is $42.6 \mathrm{kN}$ and occurs in the calculation variant $B$. For the horizontal mandrel, the maximum reaction force value $57.9 \mathrm{kN}$ - occurs in variant $E$, where the load from a special wheeled vehicle is applied asymmetrically by moving it towards the lateral edge of the ramp. The contact surface of the tire of this vehicle is then in the area of the attached edge of the connection to the spindle.

\section{Concept of mobile floating platforms}

The discussed design modifications of a single cassette have expanded thepossibility of configuring floating objects based on adjustable displacement cassettes. It is possible to compare different ferry options depending on the required load area and/or load capacity. Due to the use of a single vehicle transporting six cassettes at one time, it is possible to create ferries, e.g. in configurations [3, 4]:
- $1 \times 6$ : six cassettes connected in series, giving a loading space of $12 \times 6.3 \mathrm{~m}$ and a displacement of 480 $\mathrm{kN}$,

- $2 \times 3$ : a set of six cassettes, two parallel assemblies of three each, giving a cargo space of $12.7 \times 6 \mathrm{~m}$ with a displacement of $480 \mathrm{kN}$.

When twovehicles transport 12 cartridges at the same time,the number of allowed configurations increases. Among them, there is the basic variant as a fragment of the double ribbon $2 \times 6$ : a set of 12 cassettes joined in two rows of six pieces, which allows to achieve a cargo area of $12.7 \times 12 \mathrm{~m}$ with a displacement of up to $960 \mathrm{kN}$.

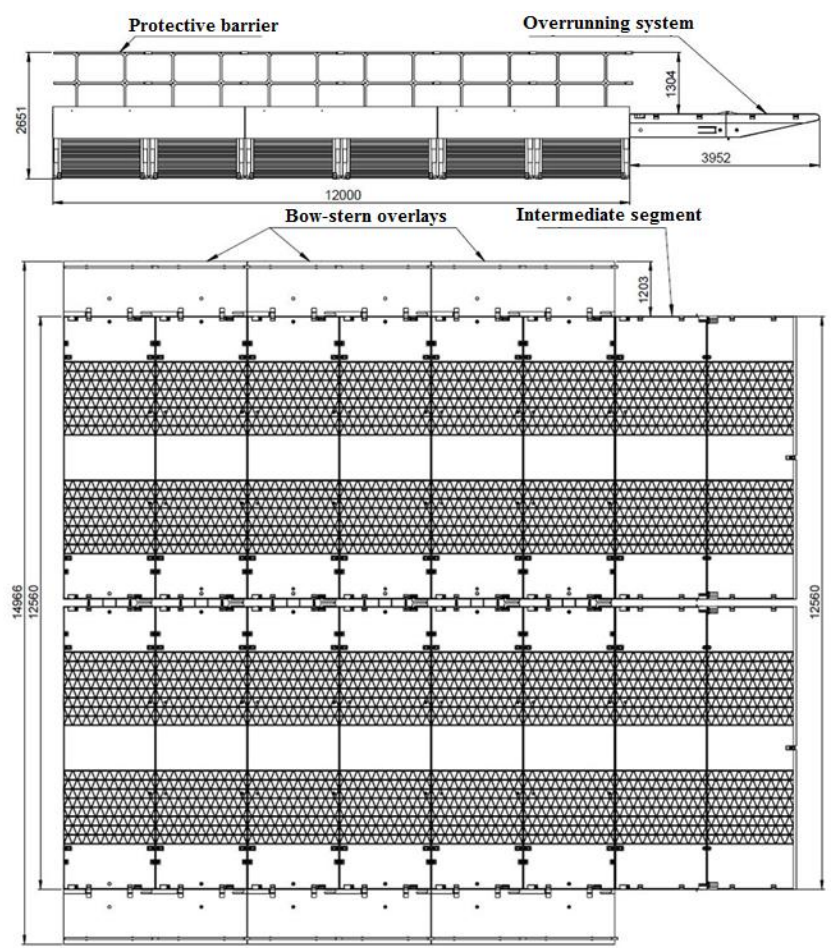

Fig. 11. Mobile floating platform in variant $2 \times 6$ includingrostralstern overlays and two overrunning-edge ramps [4]

In addition, if two bow-stern overlays are used, the operating space of each ferry variant increases by $2.4 \mathrm{~m}$ on the object's width. The ferry configurations do not include dimensions of ramps.

Selection of the propulsion and anchoring system was carried out for the ferry in a $1 \times 6$ configuration based on analytical calculations [3, 4, 7]. Determining the water pressure of $2.5 \mathrm{~m} / \mathrm{s}$ per vessel, the minimum nominal propulsion power of the propulsion engine has been set at $2 \mathrm{~m} / \mathrm{s}$. On this basis, two outboard engines DF80A of $80 \mathrm{hp}$ were selected using the SUZUKI Outboard Engine manufacturer's technical specifications. The anchoring system has also been selected based on the water pressure for the assumed configuration of the $1 \times 6$ ferry and assuming the use of a floating anchor of approximately $400 \mathrm{~N}$ and a $10 \mathrm{~m}$ long steel rope. With such an assumption, only one anchor can be used, but if the ferry is used at speeds above $2 \mathrm{~m} / \mathrm{s}$, it is possible to multiply the anchors, which will also improve the stability of the floating platform.

\section{Conclusions}

There are currently many different designs of mobile platforms and floating ferries, but most of these units are large in size, causing significant transport problems. 
Floating cassette with variable displacement with sliding bottom is characterized by unmatched relation of usable capacity to dimensions and mass. Modifications to a single floating cassette reduce overall weight and extend the range of potential uses of floating systems built on it. An increase in such constructive susceptibility is confirmed, for example, in the possibility of building any ferry configurations or bridges. The bow-stern overlays provide increased operating space for the crew and displacement of the entire system due to their construction, as well as reduced drag on the water. At the same time, they provide quick and easy assembly or disassembly.

Their additional advantage is the possibility of using a roller shutter system, which provides ballistic protection for a flexible inflatable pontoon. The roller shutter system also provides a streamlined shape of the floating object below the bow and stern overlays, i.e. at different stages of the pontoon filling and the degree of opening of the cassette bottom.

The design of the overrun-to-shore ramp will allow the loading/unloading process to take place on board the ferry, and can also be used for crossing between the ribbon bridge and the shore. The ramp structure has been tested for strength using numerical methods for safe use in different support and load conditions. In the ramp pattern, external stiffeners are not included, which may affect the local strain and deformation in areas of direct contact with wheels or tracks of vehicles with roadways.

\section{REFERENCES}

1. https://cnim.com/en/motorized-floating-bridge-pfm (access: 2017).

2. Chłus K., Derewońko A., Krasoń W. „Experimental and numericalverification of the pontoon bridge section". Journal of KONES-2013 Powertrain and Transport. 20, 1 (2013): pp. 3540.

3. Krasoń W. „Założenia do modyfikacji pojedynczej kasety i budowy promówz napędem własnym na bazie kasety o zmiennej wyporności". Warszawa: Wojskowa AkademiaTechniczna, 2016.

4. Sławek P. „Opracowanie i analiza numeryczna rozwiązań konstrukcyjnychmobilnej modułowej platformy pływającej". Thesis. Warszawa: 2017.

5. Hyper Mesh. „User's Guide”. Altair Engineering Inc., 2007.

6. MSC.Software. „MSC.Patran/MSC.Nastran - Reference Manual'.2005.

7. Bursztynowski Z. „Mosty wojskowe. Część III: Mosty pływające". Warszawa:Wydawnictwo WAT, 1970. 